\title{
Analysis of Nitride Layers on ARMCO Pure Iron: The Powder-Pack Nitriding Process
}

\author{
M. Ortiz-Domínguez ${ }^{1}$, O. A. Gómez-Vargas ${ }^{2}$ I. Simón-Marmolejo ${ }^{1}$, M. A. Flores-Rentería ${ }^{1}$, L. E. \\ Martínez-Martínez $^{1}$, A. Cruz-Avilés ${ }^{1}$, M. A. Paredes-Rueda ${ }^{2}$ \\ 1. Department of Mechanical Engineering, Universidad Autónoma del Estado de Hidalgo-Campus \\ Sahagún, Hidalgo, México. \\ 2. Department of Mechanical Engineering, Instituto Tecnológico de Tlalnepantla, EdoMéx, México.
}

The nitriding of iron and steel is of considerable technological importance, because it can make a pronounced improvement in the fatigue, the wear, and the corrosion resistance of these materials. Nitriding on the surface of ferrous alloys results in the formation of a compound layer of $\gamma^{\prime}-\mathrm{Fe}_{4} \mathrm{~N}_{1-\mathrm{x}}$ and $\varepsilon-\mathrm{Fe}_{3} \mathrm{~N}$ nitrides or a mixture of $\gamma^{\prime}$ and $\varepsilon$ with a nitrogen diffusion zone beneath the nitride layer. The broad range of nitride layer properties needed for different applications requires good control of nitriding process [1-3]. In the powder-pack nitriding process, which is similar to the powder-pack carburizing process, samples are placed in an annealing box with a powder mixture that consists of nitrogen-rich material and an activator. The nitriding temperatures are between $723 \mathrm{~K}$ and $823 \mathrm{~K}$, a range in which the nitriding potential is a function of the mount of activator used in the powder mixture. The powder-pack method is a low-cost process particularly suited for the formation of uniform nitride layers on structural alloy components with complex shapes and of various sizes [4-5]. In this study, the microstructure of the $\gamma^{\prime}-\mathrm{Fe}_{4} \mathrm{~N}_{1-\mathrm{x}}$ and $\varepsilon-\mathrm{Fe}_{3} \mathrm{~N}$ layers formed on an ARMCO pure iron surface have been investigated at different temperatures by the powder-pack process.

The powder-pack nitriding process (Pulnieren (C, H. E. F. Durferrit method) was conducted on square commercial samples of ARMCO pure iron with a thickness of $5 \mathrm{~mm}$. Prior to the nitriding process, the samples were ground, polished cleaned at room temperature in $\mathrm{H}_{2} \mathrm{SO}_{4}$ for $10 \mathrm{~s}$, and dried and stored in clean-room conditions. The samples were embedded in a closed in a closed cylindrical case (AISI 304L stainless steel) having a boron powder mixture inside with an average particle size of $30 \mu \mathrm{m}$. The pack method in the powder mixture consisting of calcium cyanamide $\left(\mathrm{CaCN}_{2}, \sim 24 \%\right.$ of $\left.\mathrm{N}\right)$ and calcium silicate ( $\mathrm{CaSi}, \sim 35 \mathrm{wt} . \%$ of the mixture) as an activator. The samples were directly immersed in the powder mixture in another stainless steel cylindrical case. The nitriding temperatures were 723,773 and $823 \mathrm{~K}$ for 2 - $12 \mathrm{~h}$ of exposure for each temperature. Nitriding followed after placing the case in a resistance furnace without the use of inert gases. Once treatment was complete, the container was removed from the furnace and slowly cooled to room temperature. The samples were cross-sectioned and resin-embedded for traditional metallographic preparation; the polished samples were etched in a $2 \%$ nital solution to observe the nitride layer depths and morphology by SEM and EDS (JEOL JSM$6360 \mathrm{LV}$ at $20 \mathrm{kV}$ ). X-Ray Diffraction (XRD) analyses of the layers were carried out with $2 \theta$ varying $20^{\circ}$ to $90^{\circ}$, using $\mathrm{CuK}_{\alpha}$ radiation and $\lambda=1.54 \AA$. Finally, to determine the nitrogen depth profiles, GlowDischarge Optical Emission Spectroscopy (GDOES) technique utilising a Horiba Jobin Yvon RF GDProfiller2 operating with an RF source at $20 \mathrm{~W}$ and an argon working pressure of $650 \mathrm{~Pa}$, the tests were carried out in the nitrided samples developed at $823 \mathrm{~K}$ with $12 \mathrm{~h}$ of exposure. Figure 1 shows the crosssections and the EDS analysis obtained by SEM at the $\varepsilon-\mathrm{Fe}_{3} \mathrm{~N} / \gamma^{\prime}-\mathrm{Fe}_{4} \mathrm{~N}_{1-\mathrm{x}}$ interphase for the nitrided ARMCO pure iron. The corresponding profile composition revealed maximum nitrogen content on the surface of 25 at $\% \mathrm{~N}$ (Fig. 2). The existence of the $\varepsilon-\mathrm{Fe}_{3} \mathrm{~N}$ and $\gamma^{\prime}-\mathrm{Fe}_{4} \mathrm{~N}_{1-\mathrm{x}}$ were verified by $\mathrm{X}$-ray diffraction (Fig. 3). The results demonstrate that the morphology of nitrided irons were homogeneous 
and flat. Figure 2 shows the profile composition with maximum nitrogen content on the surface of 25 at $\% \mathrm{~N}$, indicating the development of two nitride layers $\left(\varepsilon-\mathrm{Fe}_{3} \mathrm{~N}\right.$ and $\left.\gamma^{\prime}-\mathrm{Fe}_{4} \mathrm{~N}_{1-\mathrm{x}}\right)$, as confirmed by XRD shown in Figure 3.

\section{References:}

[1] H. Du and J. Agren, Z. Metallkd. 86 (1995), p. 522.

[2] J. R. Davis, "Surface Hardening of Steels: Understanding the Basics", 1 st ed. ASM, Ohio, p. 213.

[3] K. H. Habig, Mater. Eng. 2 (1980) p. 83.

[4] Z. D. Xiang and P. K. Datta, Surf. Coat. Technol. 179 (2004), p. 95.

[5] K. Y. Li and Z. D. Xiang, Surf. Coat. Technol. 204 (2010), p. 2268.

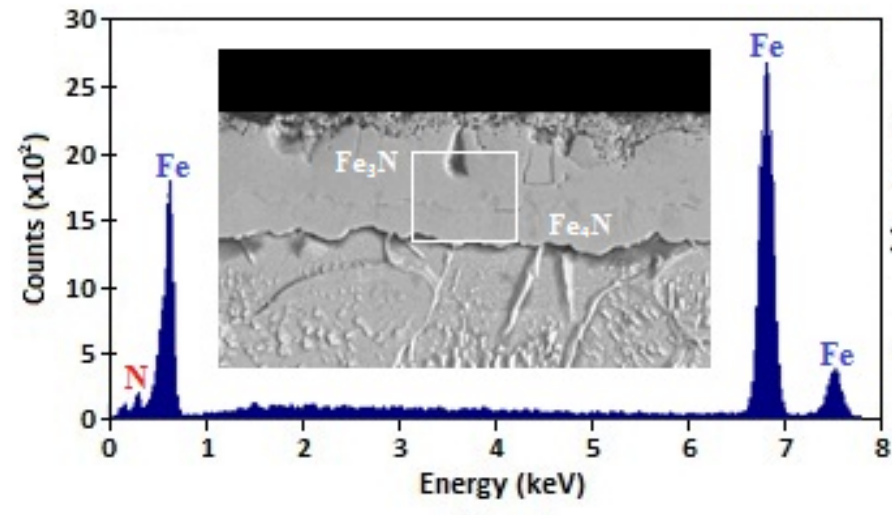

Fig. 1

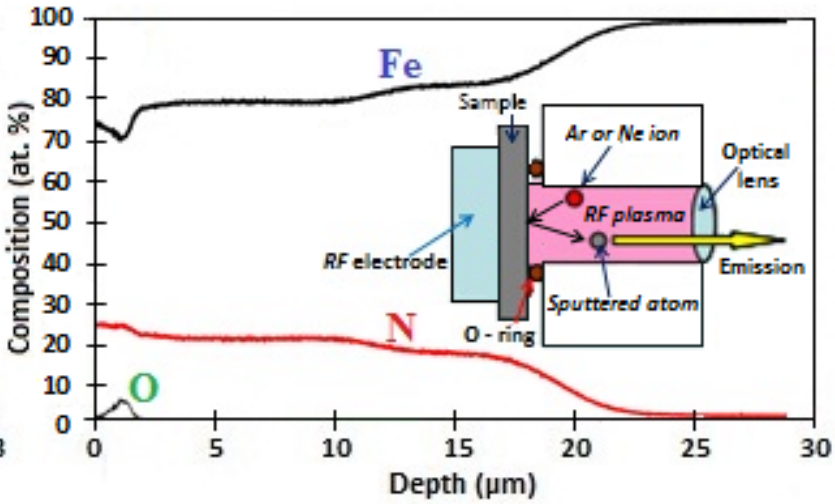

Fig. 2

Figure 1. Image (SEM) cross-sectional of boro-nitrided ARMCO pure iron showing the produced layers and GDOES (Figure 2) spectrum of the elements distribution from the surface to the interior of the nitride $\gamma^{\prime}-\mathrm{Fe}_{4} \mathrm{~N}$ and $\varepsilon-\mathrm{Fe}_{3} \mathrm{~N}$ layers at $823 \mathrm{~K}$ with $12 \mathrm{~h}$.

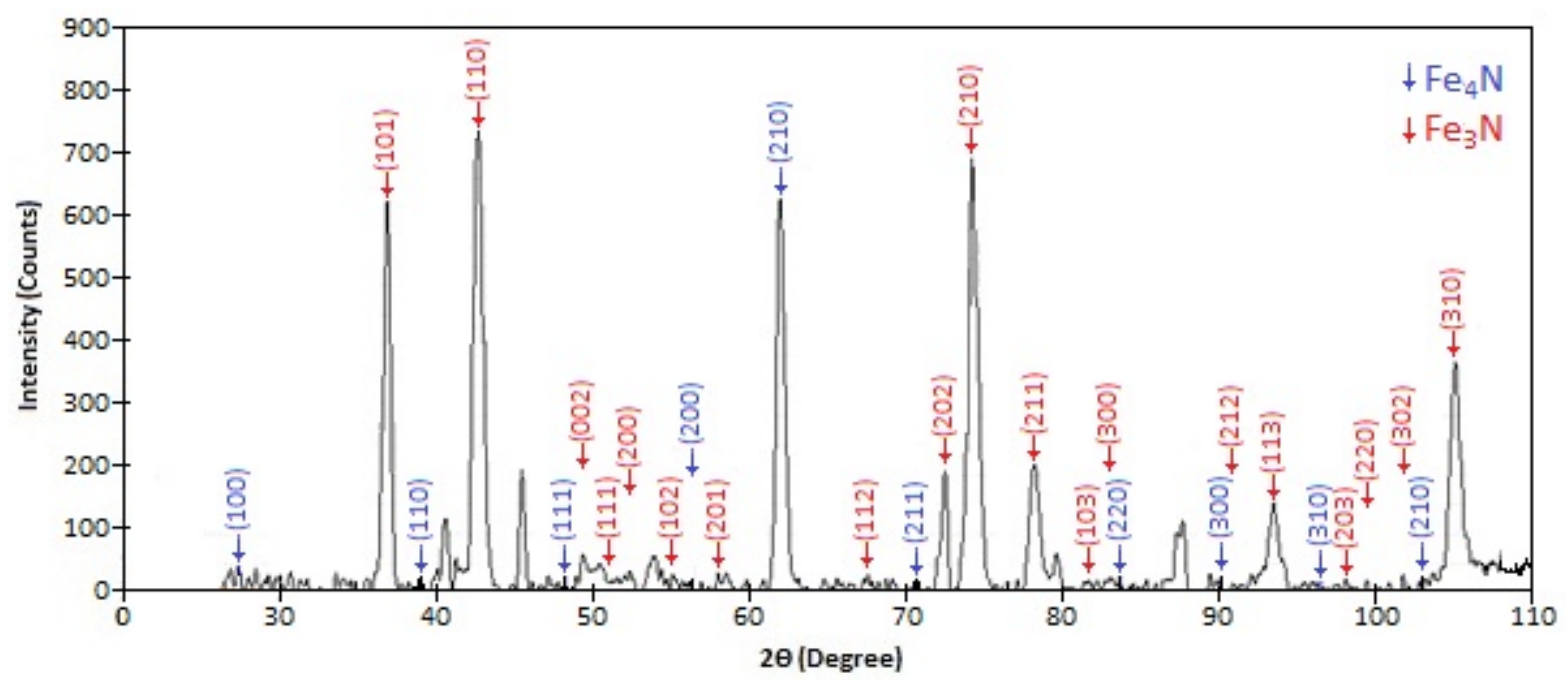

Figure 3. XRD from the cross-section of nitride coating, with $823 \mathrm{~K}$ for $12 \mathrm{~h}$ of exposure time. 